\title{
Determination of Mercury in Selected Polluted Sediments using HPLC-ICP-MS in Westbank Area, Western Cape, South Africa
}

\author{
Shirley Le Roux ${ }^{\mathrm{a}}$, Priscilla Baker ${ }^{\mathrm{a}, \boldsymbol{t}}$ and Andrew Crouch ${ }^{\mathrm{b}}$ \\ ${ }^{a}$ SensorLab, Chemistry Department, Private Bag X17, University of the Western Cape, Bellville, 7535, South Africa. \\ ${ }^{b}$ Faculty of Science, University of the Witwatersrand, Private Bag 3, Johannesburg, 2050, South Africa.
}

Received 15 October 2015, revised 15 March 2016, accepted 16 March 2016.

\begin{abstract}
High selectivity, excellent linearity and reproducibility were achieved using HPLC-ICP-MS method for mercury in sediments. The HPLC-ICP-MS method reported previously for mercury in biota analysis was adapted in terms of operational consumables and optimized for the efficient mercury determination in riverbed sediments; a first for South Africa. Results obtained for real environmental samples, were verified by Direct Mercury Analysis (DMA) by an accredited laboratory. The determination of inorganic and organic mercury compounds in sediments was based on the complexation of mercury compounds with cysteine. The separation was achieved on a reversed-phase $\mathrm{C}_{18}$ column $(15 \mathrm{~cm} \times 4.6 \mathrm{~mm}$ id $)$ using aqueous $0.1 \% \mathrm{w} / \mathrm{v} \mathrm{L}$-cysteine $\cdot \mathrm{HCl}+0.1 \%$ $\mathrm{w} / \mathrm{v}$ L-cysteine mobile phase at a flow rate of $0.8 \mathrm{~mL} \mathrm{~min}^{-1}$ at ambient temperature. The method was found to be suitable for the routine analysis of $\mathrm{Hg}$ compounds in sediments as well as aqueous media and was developed to determine the influence of humic substances on the bioavailability of mercury species. The results were comparable and consistent with those determined with a Direct Mercury Analyzer. The detection limit for methylmercury, ethylmercury and inorganic mercury were lower than $10 \mathrm{ng}^{-1}$ and recoveries for spiked samples was $>90 \%$. The accuracy of the method was assessed by the analysis of certified reference material (European Reference Material ERMCC580 and Tort-2) and found to be in good agreement. Mercury concentration was determined in sediments collected from the Eerste Kuils River, Westbank area, Kuilsriver, Western Cape, South Africa. Mercury concentration was determined to vary from $2-14 \mathrm{ng} \mathrm{g}^{-1}$ (w.wt).
\end{abstract}

KEYWORDS

Speciation, validation, complexation, bioavailability.

\section{Introduction}

Anthropogenic sources as well as natural contributions (e.g. volcanic activity and evaporation from the oceans) have increased $\mathrm{Hg}$ levels in the environment. Mercury $(\mathrm{Hg})$ is widely used as a catalyst in the manufacture of sodium hydroxide, gold mining, manufacture of batteries and thermometers, as fungicides, herbicides and disinfectants. ${ }^{1}$ As a highly toxic metal, it is considered to be a global pollutant ${ }^{2,3}$. South Africa is the world's sixth largest producer of coal; ;,4,5 coal provides about $75 \%$ of the country's primary energy needs and over $90 \%$ of its electricity is coaldriven. ${ }^{3,7}$ Almost all the $\mathrm{Hg}$ present in the coal, $>90 \%{ }^{8}$ is vapourized and released in the form of elemental $\mathrm{Hg}$. The largest emissions of $\mathrm{Hg}$ in South Africa are from coal-fired power plants, with an estimated contribution of $78 \%{ }^{6}$ Anthropogenic $\mathrm{Hg}$ emissions are likely to increase as human dependency or demand for energy increases. Masekoameng et al. ${ }^{6}$ studied the trends in the anthropogenic mercury emission for South Africa and showed a general increase in emissions with a contribution of up to $2 \%$ of total global emissions. There are not many reported studies ${ }^{9}$ about the $\mathrm{Hg}$ emissions from natural sources although they could be an important contribution to total $\mathrm{Hg}$ emission. ${ }^{6}$ Health impacts of potentially harmful elements, stemming from sulphide mineralization, mining or ore processing and mine waste disposal are generally not well documented. ${ }^{9}$ Disposal of mine waste in tailing dams could be a large risk to the adjacent environment due to the potential of

* To whom correspondence should be addressed. E-mail: pbaker@uwc.ac.za migration of these toxic, heavy metals to the surrounding area. Inadequate management of these tailing dams has led to serious environmental problems..$^{10}$ It is important to understand the environmental impact of heavy metals entering the surrounding area from these tailing dams. ${ }^{11,12}$ In South Africa and neighboring countries there is an increase in illegal small-scale mining of disused gold mines. ${ }^{13}$ These mining operations use entirely $\mathrm{Hg}$ extraction methods for gold recovery. In the population at three sites along the South Africa coast Channa et al. ${ }^{13}$ determined $\mathrm{Hg}$ levels of $1.15 \mu \mathrm{g} \mathrm{L}^{-1}$ and $1.67 \mu \mathrm{g} \mathrm{L}^{-1}$ in maternal and cord blood, respectively. Other possible sources of $\mathrm{Hg}$ emissions include products of the incineration and treatment of waste at a municipal waste site and medical waste incinerators. $\mathrm{Kuhn}^{14}$ found excessive levels of $\mathrm{Hg}$ in some of the residents of an area in Cape Town (South Africa) living in close proximity to a waste disposal site, an industrial site that housed a brick factory that burned fossil fuels, and to an oil reclamation plant (potentially resulting in airborne $\mathrm{Hg})^{15}$ (Dalvie and Ehrlich ${ }^{15}$ ). Dalvie and Ehrlich ${ }^{15}$ found that the urinary $\mathrm{Hg}$ levels of residents in the exposure area however were not a major health factor as the levels determined were below levels associated with adverse health effects.

Mercury deposits mainly in sediments, where it finally ends up in aquatic systems. ${ }^{16,17}$ Sediments are capable of immobilizing toxic metals but this does not guarantee that the metals are safely removed from aquatic systems. Metals can be reintroduced into the aquatic systems if the solubility, mobility and bioavailability 
increase due to different environmental factors such as $\mathrm{pH}$, salt concentration, the presence of complexing agents, and changes in redox potential or chemical form. ${ }^{18}$ Sediments can be a long-term source of $\mathrm{Hg}$ to surface waters. ${ }^{19}$ Walters et al. ${ }^{20}$ mapped the spatial patterns of $\mathrm{Hg}$ distribution and bioaccumulation in water resources in the 19 designated Water Management Areas (WMAs) across South Africa. Higher Hg concentration where reported in areas closer to coal-fired power stations and gold mining. . $, 5,20-22^{-22}$

A metal's mobility, accumulation, bioavailability and toxicity depend on the chemical form of the metal. ${ }^{1,23,24}$ Mercury occurs in three chemical forms, metallic or elemental mercury $\left(\mathrm{Hg}^{0}\right)$, inorganic mercury $\left(\mathrm{Hg}^{2+}\right)$, and methylated forms that include the organic forms of $\mathrm{Hg}$ such as, methylmercury (MeHg), etylmercury $(\mathrm{EtHg})$ and dimethylmercury $(\mathrm{DMHg}){ }^{25-26}$ The organic forms are more toxic than their inorganic counterparts, and have been shown to affect the central nervous system of humans..$^{25}$ Mercury speciation studies are therefore essential to monitor the levels of these species in water, soil and biota to determine the toxic effect of $\mathrm{Hg}$ on the environment. Monitoring of the distribution of metals, including $\mathrm{Hg}$ species, is important in order to control pollution from industrial processes.

There are a number of very efficient analytical techniques capable of determining $\mathrm{Hg}$ levels in different matrices. The United States Environmental Protection Agency (USEPA) has published methods for measuring low levels of $\mathrm{Hg}$ and $\mathrm{MeHg}$ in water and biota, using gas chromatography (GC) and cold-vapour atomic fluorescence spectrophotometry (CVAFS) (USEPA Method 1631 and 1630, 1999). The best established and most widely used method for mercury speciation analysis is gas chromatography with an electron capture detector in methods modified from the Westöö procedure. The disadvantage is that it is time-consuming, uses hazardous organic solvents and it requires volatile, thermally stable derivatives. ${ }^{27,28}$ Another disadvantage is that the detector is not selective for $\mathrm{Hg}$ but responds to any compounds containing halogens. By using this method, time-consuming clean-up procedures are used to eliminate interferences. $^{29,30}$

New methods are constantly being developed and HPLC is one that can rapidly and efficiently separate a variety of compounds. A disadvantage of the HPLC-method is that it lacks sufficient concentration detection sensitivity. Several detectors have been developed that can substantially lower the sensitivity of this analytical technique, including inductively coupled plasma (ICP), inductively coupled plasma mass spectroscopy (ICP-MS), and electrochemical detection. These methods have shown high selectivity, excellent linearity and reproducibility in analysis for $\mathrm{MeHg}$ and other forms of $\mathrm{Hg} \cdot{ }^{31} \mathrm{~A}$ disadvantage of using ICP as a detector for HPLC is that the mobile phase should be carefully chosen as solvents such as methanol and acetonitrile are not compatible with the argon plasma. ${ }^{2}$ Mobile phases which contain high concentrations of salts and buffers can clog the cones of the nebulizer which can produce changes in sensitivity. ${ }^{32}$

The popular analytical method for the determination of total mercury used to be by gold trap amalgamation followed by cold-vapour atomic absorption or cold-vapour atomic fluorescence spectroscopy. ${ }^{33-35}$ Time-consuming digestion of the sample however is required. The use of the direct mercury analyzer (DMA) is becoming very popular for total mercury analysis. ${ }^{3}$ It is the standard method employed by the CSIR (Council for Scientific and Industrial Research; Natural Resources and the Environment) for total mercury analysis. No pre-treatment of the sample is required and it is suitable for solid and liquid samples. Because no digestion of the sample is needed there is no need for corrosive chemicals and the production of hazardous waste is thus minimized. The method also has a very good detection limit. ${ }^{1}$

Here we present for the first time a simplified method for the analysis of $\mathrm{MeHg}$, EtHg and $\mathrm{Hg}^{2+}$ in environmental samples by HPLC-ICP-MS. The method describe here has been adapted in terms of solvents used for extraction, efficiency of extraction as well as simplification of sample handling. A lower injection volume and lower flow rate gave excellent separation within $12 \mathrm{~min}$. An Agilent 7900 ICP-MS system used in the analysis is fitted with standard nickel cones, glass concentration nebulizer with a generator collision/reaction cell, a 4th generator, octopole reaction system which provides optimized operating conditions for helium (He) collision mark. It uses an advanced collision/ reaction technology to ensure accurate results with minimal polyatomic interferences derived from the sample matrix. Here we report on the improved sensitivity $(<5 \%)$ achieved as a result of method modification.

\section{Sampling Site}

Sediments samples were collected using standard CSIR protocols, ${ }^{5}$ up to a depth of $12 \mathrm{~cm}$. Sediment samples were transferred to acid cleaned sample jars, stored frozen in plastic bags until digestion and analysis. The sampling site was at the Eerste Kuils River, Westbank area, Kuilsriver, Western Cape, South Africa (Fig. 1). The Eerste River rises on Dwarsberg $60 \mathrm{~km}$ east of Cape Town at the head of Jonkershoek Nature Reserve. The Eerste River is a short river; with a length of $40 \mathrm{~km}$. The major tributary, the Kuils River, is approximately $30 \mathrm{~km}$ long to its point of flowing together with the Eerste River. The Eerste River site $\left(33^{\circ} 05^{\prime} \mathrm{S}\right.$, $\left.18^{\circ} 46^{\prime} \mathrm{E}\right)$ is approximately $36 \mathrm{~km}$ southeast of Cape Town.

\section{Experimental}

\subsection{Reagents}

The $\mathrm{CuSO}_{4}, \mathrm{HNO}_{3}(65 \%), \mathrm{CH}_{2} \mathrm{Cl}_{2}$, cysteine and cystein $\cdot \mathrm{HCl}$ were reagent grade purity and purchased from Merck. Stock solutions of $\mathrm{MeHg}, \mathrm{EtHg}$ and $\mathrm{Hg}^{2+}$ were prepared from the respective chloride salts obtained from Aldrich-Sigma at a concentration of $1.0 \mathrm{~g} \mathrm{~L}^{-1}$ each. A stock solution of $\mathrm{Hg}^{2+}$ was prepared by dissolving its chloride salt in $0.1 \% \mathrm{HCl}$. Stock solutions of $\mathrm{MeHg}, \mathrm{EtHg}$ and $\mathrm{PhHg}$ were prepared by dissolving the respective salts in HPLC grade methanol and diluting with ultrapure water purified by a Milli-Q (Millipore) system. All stock solutions were stored in a refrigerator. The standard solutions were prepared daily by appropriate dilutions with purified water.

\subsection{Sample Preparation and HPLC-ICP-MS Analysis}

A $0.5-1.5$ g sediment sample was weighed into a $50 \mathrm{~mL}$ polypropylene centrifuge tube to which $2 \mathrm{~mL}$ of $\mathrm{CuSO}_{4}(1 \mathrm{M}), 10 \mathrm{~mL}$ of $\mathrm{HNO}_{3}(3 \mathrm{M})$ and $10 \mathrm{~mL}$ of $\mathrm{CH}_{2} \mathrm{Cl}_{2}$ was added. The centrifuge tube was tightly capped and vigorously shaken for $30 \mathrm{~min}$ on a Gerhardt mechanical shaker. The mixture was then centrifuged at $3000 \mathrm{rpm}$ for $30 \mathrm{~min}$. About $5 \mathrm{~mL}$ of the $\mathrm{CH}_{2} \mathrm{Cl}_{2}$ was pipetted into $40 \mathrm{~mL}$ of deionized water. The water $/ \mathrm{CH}_{2} \mathrm{Cl}_{2}$ mixture was heated in a waterbath (Memmert WNB 7-45, Germany) at $45^{\circ}$ for solvent evaporation until no visible layer of $\mathrm{CH}_{2} \mathrm{Cl}_{2}$ solvent was left. The temperature of the water bath was increased to $75^{\circ} \mathrm{C}$, the sample purged with $\mathrm{N}_{2}$ to remove the solvent residue, and the sample was diluted to $40 \mathrm{~mL}$ with deionized water before analysis. These samples were used for analysis by HPLC-ICP-MS. Analysis was performed on an Agilent 1100 series. Separation was achieved by using a Synergi Hydro-RP $\mathrm{C}_{18}, 150 \times 4.6 \mathrm{~mm}$ i.d. column. 


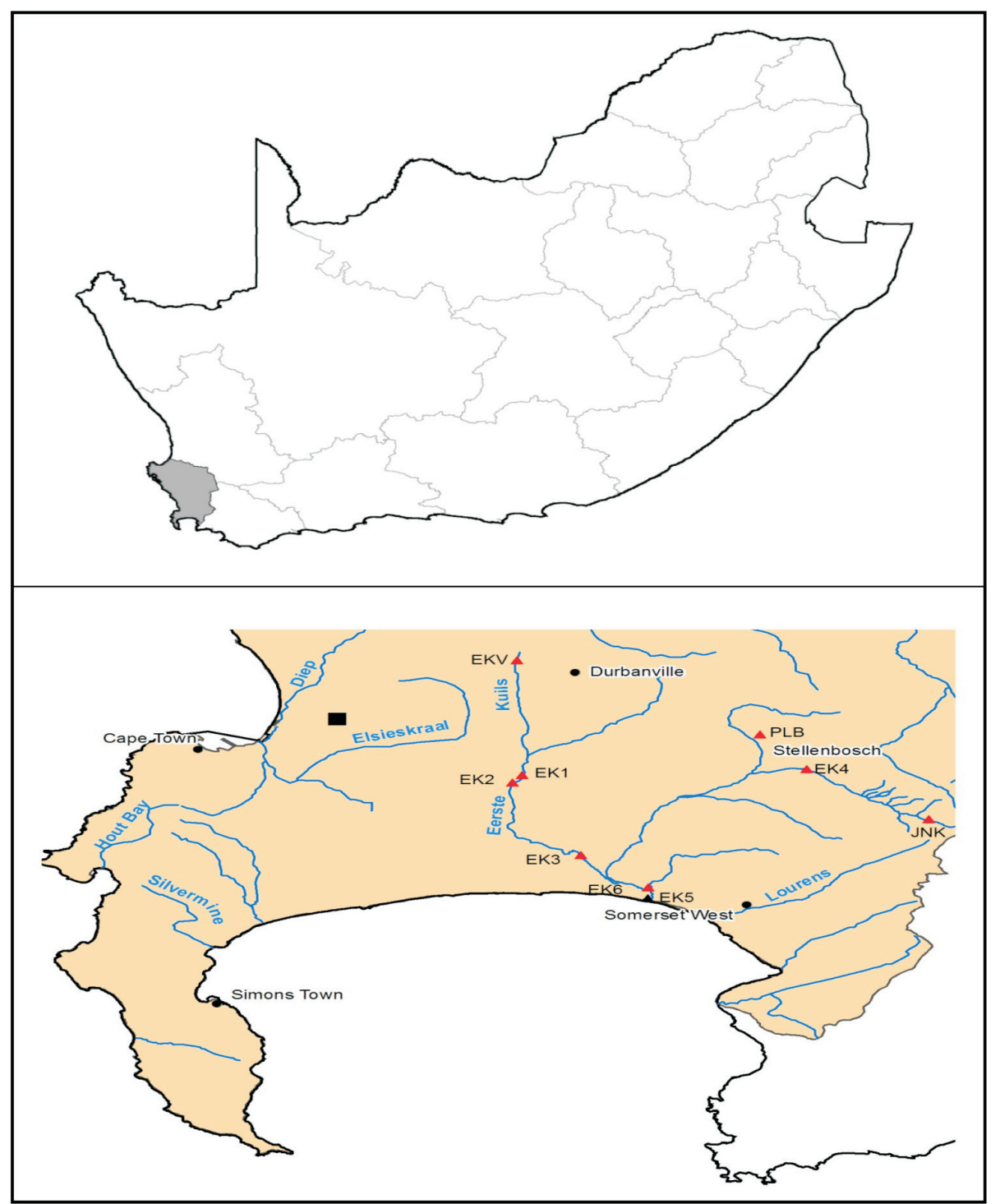

Figure 1 Map of the sampling area, Eerste Kuil River, in the Western Cape, South Africa (map supplied by CSIR databases, at a fixed fee).

The chromatographic operating conditions used for the determination are listed in Tables $1 \& 2$. The mobile phase used was prepared in the same way as a method described by Hight and Cheng ${ }^{28}$. The mobile phase was prepared by volume and consisted of aqueous $0.1 \% \mathrm{w} / \mathrm{v}$ L-cysteine $\cdot \mathrm{HCl}+0.1 \% \mathrm{w} / \mathrm{v}$ L-cysteine. The mobile phase was filtered through a $0.45 \mu \mathrm{m}$ Millipore membrane and sonicated before use. To obtain reproducible results the mobile phase and the standards were prepared daily.

\subsection{Direct Mercury Analyzer}

The sediment samples was analyzed for total mercury concentration with a direct mercury analyzer. The DMA uses a dual cell atomic absorption spectrometer to determine elemental $\mathrm{Hg}$ and absorption was measured at a wavelength of $253.65 \mathrm{~nm}$. A 0.2-0.5 g sediment sample was placed into quartz boats, the sample was weighed, dried for a set period and then thermally decomposed. This process heated the sample to release the mercury and the vapours were carried by an oxygen flow to an amalgamator for selective trapping of mercury on a gold trap. After a short heating period, the mercury released was measurement by atomic absorption. ${ }^{1,3}$ Triplicates were run on all of the samples, and standards reference material was run between every eight samples.

\section{Results and Discussion}

\subsection{Chromatograms of a Mixed Standard and a Sediment Sample obtained by HPLC-ICP-MS}

The retention time of $\mathrm{MeHg}, \mathrm{EtHg}$ and inorganic $\mathrm{Hg}$ was verified by single standard analysis. A cocktail standard was prepared by mixing $\mathrm{MeHg}$, EtHg and inorganic $\mathrm{Hg}$. A $20 \mu \mathrm{L}$ of the prepared standard was injected and analyzed. The peaks of the mixed standards were well resolved and the different mercury species all elute within $10 \mathrm{~min}$ (Fig 2). In all the sediment standards analyzed only inorganic $\mathrm{Hg}$ (Fig 3) was detected in the sediment samples.

\subsection{Linearity and Detection Limits}

Calibration curves for each mercury species were constructed. The calibration graphs containing the information for the determination of the mercury species is illustrated in Figs. 4-6. The optimum conditions for separation as mentioned in Tables 1 \& 2 were used to obtain the required data.

Chromatographic separation of the three compounds was achieved within $12 \mathrm{~min}$ at ambient temperature. Retention times were $2.5 \mathrm{~min}, 4.5 \mathrm{~min}$ and $10.8 \mathrm{~min}$ for $\mathrm{Hg}^{2+}$, $\mathrm{MeHg}$ and $\mathrm{EtHg}$, respectively. Linear regression data for $\mathrm{Hg}^{2}, \mathrm{MeHg}$ and $\mathrm{EtHg}$ are presented in Table 3. A calibration curve for each of the four 


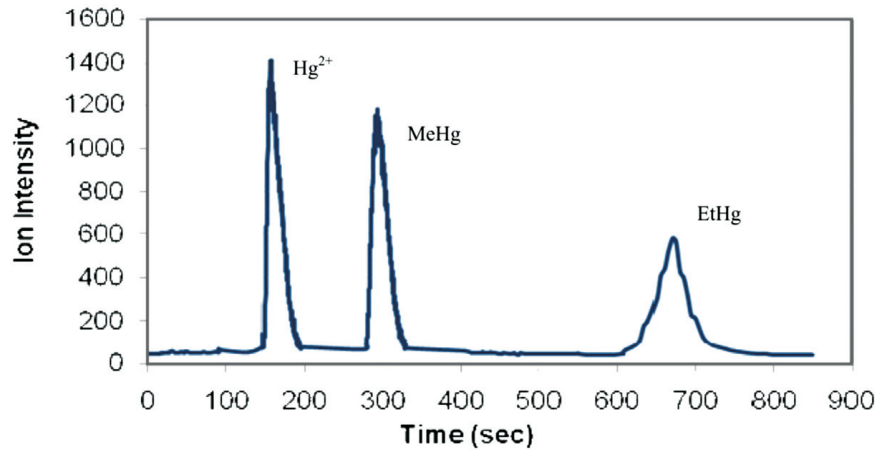

Figure 2 Chromatogram of a $10 \mathrm{ppm}$ standard solution of $\mathrm{MeHg}$, EtHg and $\mathrm{Hg}^{2+}$ determined with HPLC-ICP-MS and using best conditions established (Tables $1 \& 2$ ).

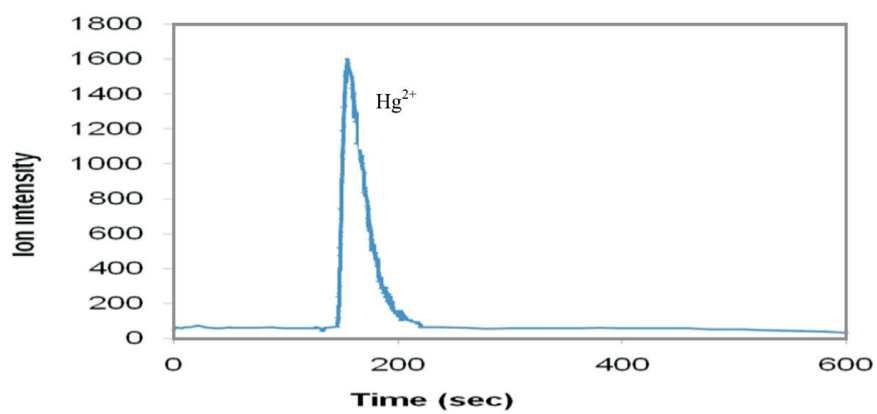

Figure 3 Chromatogram of a sediment sample obtained from the Westbank area determined with HPLC-ICP-MS and using best conditions established (Tables $1 \& 2$ ).

mercury species were obtained from three standards and were found to be linear over the concentration range $0.5-20 \mu \mathrm{g} \mathrm{L}^{-1}$. The correlation coefficient was higher than 0.99 for the three compounds.

The analytical protocols produced calibration data which leads to the statistic results as presented in Tables $1 \& 2$. All statistical data were reported at $95 \%$ confidence level. The detection limit defined as the calculated amount of the analyte which corresponds to a signal equal to three times the standard deviation of six representative blank samples ${ }^{33}$ is listed in Tables $3 \& 4$ and was found to be $2 \mathrm{ng} \mathrm{L}^{-1}$ or less for all the species. The limit of detection (LOD) and limit of quantification (LOQ) values were determined using a signal-to-noise ratio of 3 and 10, respectively.

\subsection{Sediment Analysis, Recovery Efficiency and Accuracy Studies}

The sediment was spiked with known quantities of the mercury species in order to determine the recovery efficiency. All analysis was done in duplicate and injected into the HPLC in triplicate. Total mercury determination was done in triplicate in the DMA. The analyte recovery rate from the spiked samples was $97.54 \%$. For all the samples only $\mathrm{Hg}^{2+}$ could be detected.

Reported values are for the mean, $n=3$. Results for the percentage recovery was within $80-100 \%$ (Tables $5 \& 6$ ), and the percentage difference of the analysis results between the two
Table 1 The operating ICP-MS conditions for the determination of $\mathrm{Hg}$ compounds.

$\begin{array}{ll}\text { RF power }(\mathrm{W}) & 1550 \\ \text { Argon plasma gas flow rate } / \mathrm{min}^{-1} & 151 \\ \text { Argon auxiliary gas flow } / \mathrm{min}^{-1} & 0.91 \\ \text { Argon nebulizer flow rate } / \mathrm{min}^{-1} & 1.171 \\ \text { Sampling depth/mm } & 8 \\ \text { Solution uptake - tuning (peristaltic pump) } / \mathrm{mL} \mathrm{min}^{-1} & 0.4 \\ \text { Solution uptake - analysis (HPLC pump) } / \mathrm{mL} \mathrm{min} & 1.0 \\ \text { Solution drain - analysis } / \mathrm{mL} \mathrm{min}^{-1} & >1.0 \\ \text { Spray chamber temperature } / \mathrm{K} & 275.15 \\ \text { Mass-to-charge ratio/m/z } & 199 ; 200 ; 202 \\ \text { Chromatographic integration time/s point } & -1 \\ \end{array}$

Table 2 The optimum operating HPLC chromatographic conditions for the determination of $\mathrm{Hg}$ compounds.

Column

Column temperature

Injection volume $/ \mu \mathrm{l}$

Flow rate $/ \mathrm{mL} \mathrm{min}^{-1}$

Pump mode

Mobile phase

Run time/min

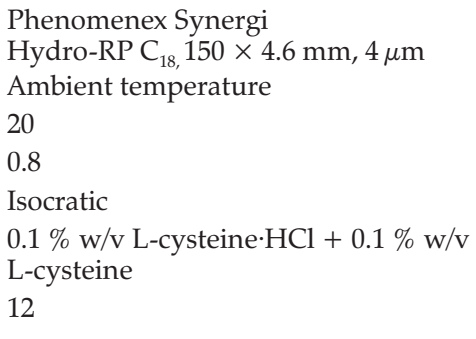

methods were within $10 \%$ difference. The confidence interval levels calculated and reported for the DMA results falls within the mean for the HPLC-ICP-MS method which implies that the two methods are statistically comparable (Table 7). The analysis of the reference sample by DMA shows a similar low value of recovery to the HPLC analysis (Tables $5 \& 6$ ). The low recovery for the HPLC method of the reference sample could be due to the high concentration of $\mathrm{Hg}^{2+}$ in the reference sample and under recovery due to extraction.

\section{Conclusion}

The sediment samples were provided by the CSIR, Natural Resources and the Environment, CSIR, Stellenbosch, South Africa. The sampling sites (at Eerste Kuil River, Westbank area, Kuilsriver, Western Cape, South Africa) are close to a landfill site, which may explain the relatively high levels of mercury obtained. The method was developed for the determination of $\mathrm{MeHg}$, EtHg and $\mathrm{Hg}^{2+}$ in soil samples. The method was validated for accuracy by analyzing reference material and spiked samples. The mobile phase used in the method used no hazardous organic materials and the extraction method was relatively quick and easy to use.

Although the method is able to determine both the organic as well as the inorganic form of mercury, none of the organic forms were found in the samples. It could be that the method was not sensitive enough to detect any organic forms present. The concentration of the $\mathrm{Hg}^{2+}$ found in the soil samples show a steady increase in concentration levels at lower depth (Figs. 7-9).

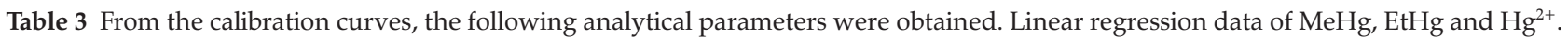

\begin{tabular}{|c|c|c|c|c|c|c|}
\hline Compound & Range/ $\mu \mathrm{g} \mathrm{L} \mathrm{L}^{-1}$ & Linear regression equation & Correlation coefficient $/ r$ & $\mathrm{LOD} / \mathrm{ng} \mathrm{L}^{-1}$ & $\mathrm{LOQ} / \mathrm{ng} \mathrm{L}^{-1}$ & Sensitivity/ng $\mathrm{L}^{-1}$ \\
\hline $\mathrm{MeHg}$ & $0.5-20$ & $8.116 x+59.35$ & 0.9992 & 0.02 & 0.20 & 0.022 \\
\hline EtHg & $0.5-20$ & $5.205 x+56.05$ & 0.9997 & 0.01 & 0.10 & 0.083 \\
\hline $\mathrm{Hg}^{2+}$ & $0.5-20$ & $5.738 x+67.50$ & 0.9996 & 0.02 & 0.20 & 0.120 \\
\hline
\end{tabular}




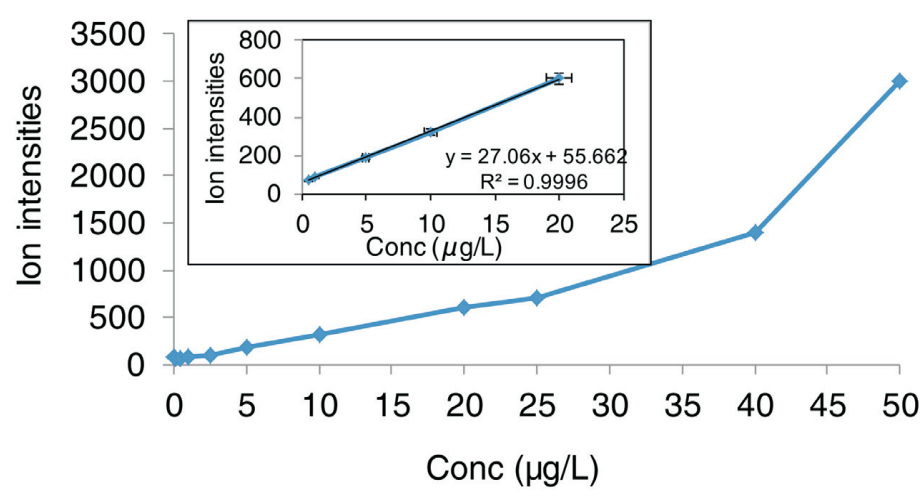

Figure 4 Calibration curve of $\mathrm{Hg}^{2+}$ standards determined with HPLC-ICP-MS under operating conditions as reported in Tables $1 \& 2$. Results are the mean of three determinations and insert shows the linear range from $0.5-20 \mu \mathrm{L}$ (error bars represent standard error, $n=3$ ).

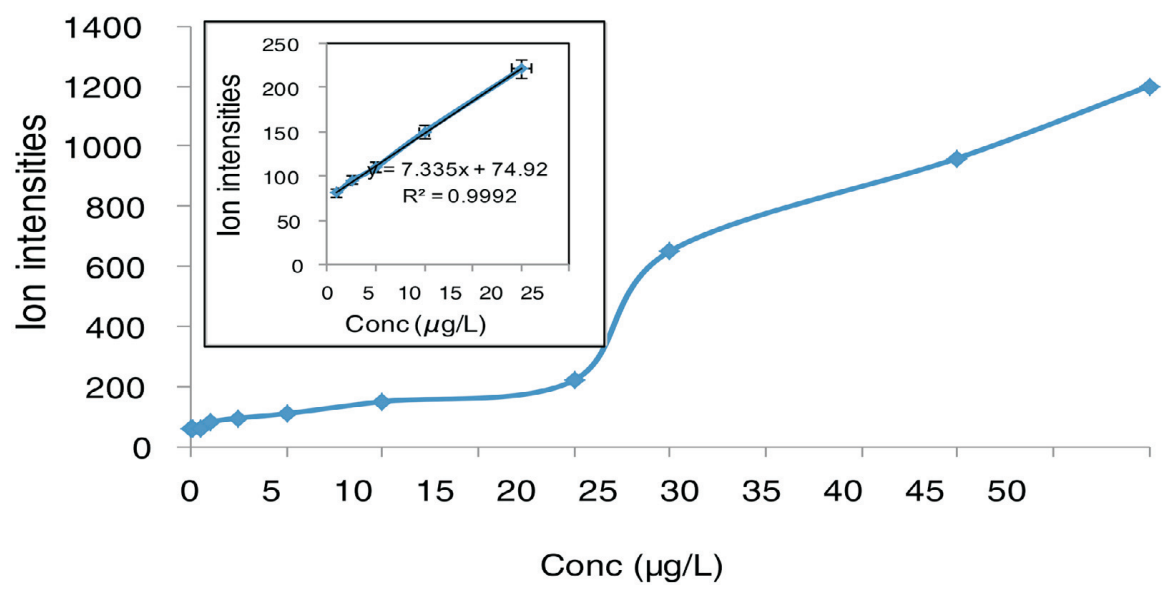

Figure 5 Calibration curve of MeHg determined with HPLC-ICP-MS obtained with operating conditions as reported in Tables $1 \& 2$. Results are the mean of three determinations and insert shows the linear range from $0.5-20 \mu \mathrm{L}$ (error bars represent standard error, $n=3$ ).

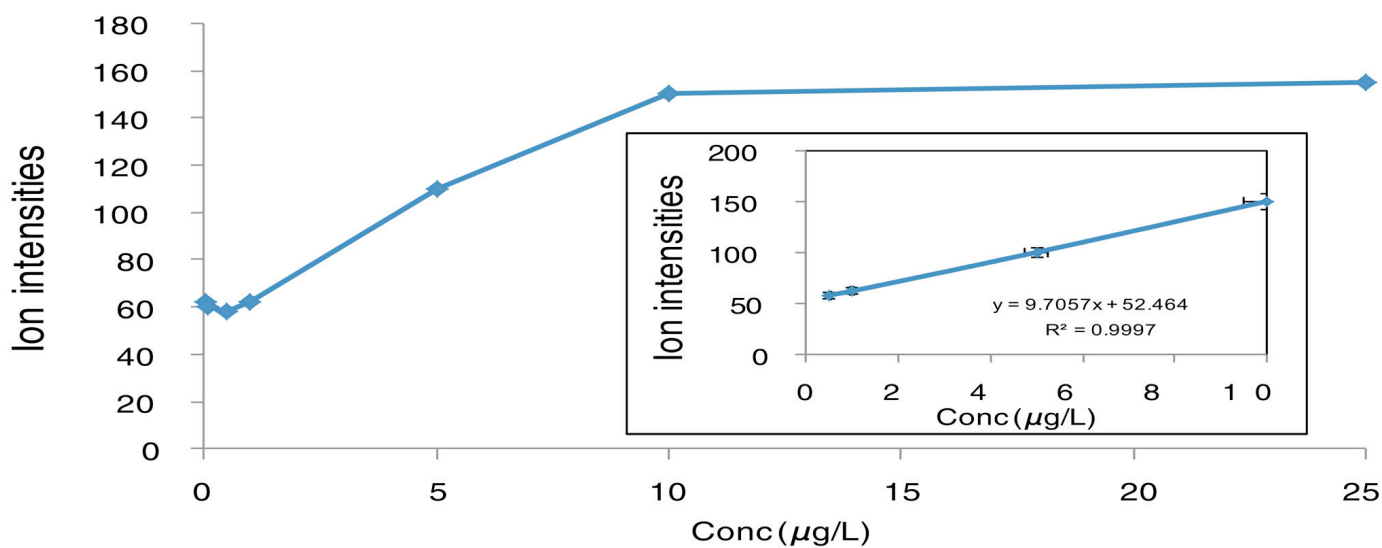

Figure 6 Calibration curve of EtHg standards determined with HPLC-ICP-MS determined with operating conditions as reported in Tables 1 \& 2. Results are the mean of three determinations and insert shows the linear range from $0.5-10 \mu \mathrm{L}$ (error bars represent standard error, $n=3$ ).

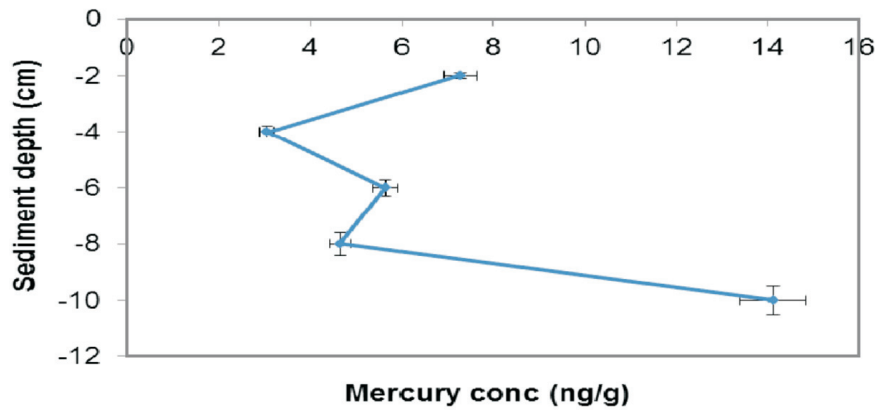

Figure 7 Variation in vertical mercury concentration distribution vs. sediments core depth at sampling site EKA, Kuils River system (error bars represent standard error, $n=3$ )

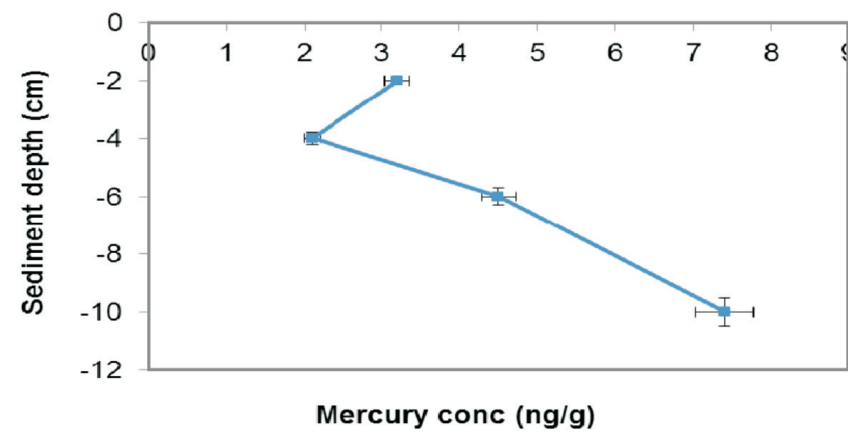

Figure 8 Variation in vertical mercury concentration distribution vs. sediments core depth at samplingsite EK 2, Kuils River system (error bars represent standard error, $n=3$ ). 


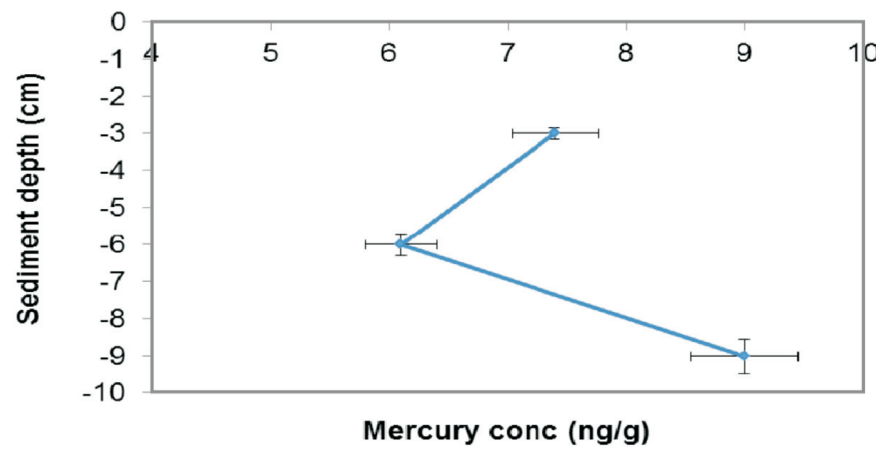

Figure 9 Variation in vertical mercury concentration distribution $v s$. sediments core depth at sampling site EKC, Kuils River system (error bars represent standard error, $n=3$ ).

Table 4 From the calibration curves, the following statistical results were obtained. Relative standard deviation values of $\mathrm{MeHg}$, EtHg and $\mathrm{Hg}^{2+}$.

\begin{tabular}{lcc}
\hline & $\begin{array}{c}\text { Relative standard } \\
\text { deviation/\% } \\
\text { Concentration } / 2 \mu \mathrm{g} \mathrm{L}\end{array}$ & $\begin{array}{c}\text { Relative standard } \\
\text { deviation } / \% \\
\text { Concentration } / 4 \mu \mathrm{g} \mathrm{L}^{-1}\end{array}$ \\
\hline $\mathrm{MeHg}$ & 3.01 & 4.12 \\
$\mathrm{EtHg}$ & 4.15 & 5.02 \\
$\mathrm{Hg}^{2+}$ & 1.25 & 2.52 \\
\hline
\end{tabular}

At a depth of $8 \mathrm{~cm}$ a slight decrease in concentration occurred at all sites except for EKC. Highest concentrations were found at levels $10-12 \mathrm{~cm}$. The dispersion of $\mathrm{Hg}$ as a function of depth as presented in Fig. 10 at the four sites showed no distinguishable trend, due to the limited sample set. Selected sediment samples provided by the CSIR, revealed an increasing trend in $\mathrm{Hg}$ concentration within the first $12 \mathrm{~cm}$ depth in riverbed samples. The samples provided by the CSIR were not specifically sampled for this work, but was in fact drawn from a wider sample base which formed part of a separate independent CSIR investigation. ${ }^{5,20}$ The samples provided were from four separate locations and taken at $2 \mathrm{~cm}$ intervals up to a depth of $12 \mathrm{~cm}$, providing us with a sample set of 17 samples which were deemed sufficient to prove the application of the method. Surprisingly an increasing trend in $\mathrm{Hg}$ concentration was observed even in this limited depth dispersion. This trend is supported by previous studies ${ }^{3,38}$ which shows an increase in $\mathrm{Hg}$ concentration up to a depth of $0-15 \mathrm{~cm}$ and then a decrease at lower depth. Each sample was analyzed three times with a RSD $<5 \%$ indicating the suitability of the method for riverbed samples.

Soil samples were spiked with both $\mathrm{MeHg}$ and $\mathrm{Hg}^{2+}$. Spike recoveries of the soil samples were $98 \%$. The recovery rate increased with less of the reference material used for extraction and on using microwave extraction. On a separate analysis using microwave digestion and the same operating conditions the recovery was determined to be $99 \%$. The method was developed for the determination of $\mathrm{Hg}^{2+}, \mathrm{MeHg}$ and $\mathrm{EtHg}$ in sediments. The extraction process was reasonably quick and easy. The method worked well for the precision of analysis as well as the accuracy determined by spiking the samples. Although the method of analysis provides for the determination of $\mathrm{Hg}^{2+}$, $\mathrm{MeHg}$ and $\mathrm{EtHg}$ only the inorganic form of mercury was detected in the soil samples. Total mercury was determined by DMA. The values obtained are in good agreement with those obtained with the DMA.

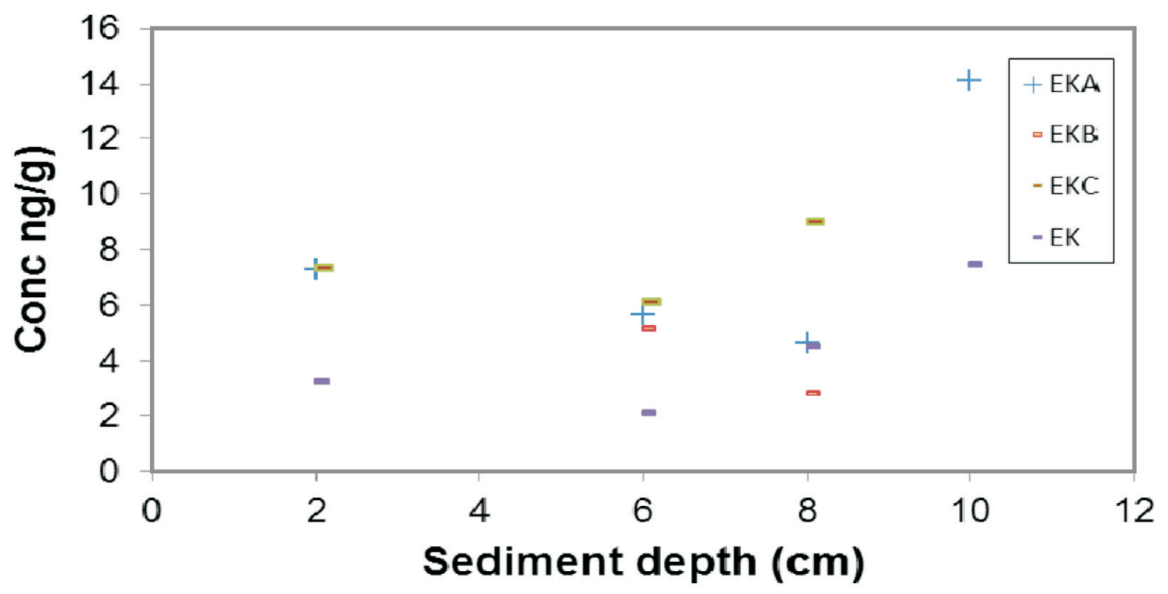

Figure 10 Variation in the distribution of mercury concentration vs. sediments core depth in sampling sites, EKA,EKB, EKC and EK, at Kuils River system.

Table 5 Certified reference sample (European Reference Material ERM-CC580) for $\mathrm{Hg}^{2+}$ and $\mathrm{MeHg}$ analyzed in triplicates with HPLC-ICP-MS.

\begin{tabular}{lcl}
\hline & Recovery value of $\mathrm{Hg}^{2+}$ & Recovery value for MeHg \\
\hline European Reference Material ERM-CC580) & $\begin{array}{c}69.8 \% \pm 15.2(\mathrm{mass} 0.1007 \mathrm{~g}) \\
132 \mathrm{mg} \mathrm{kg}^{-1} \pm 3 \mathrm{mg} \mathrm{kg}^{-1}\end{array}$ & $\begin{array}{c}89.3 \% \pm 0.0281(\mathrm{mass} 1.0003 \mathrm{~g}) \\
0.0755 \mathrm{mg} \mathrm{kg}^{-1} \pm 0.0037 \mathrm{mg} \mathrm{kg}^{-1}\end{array}$ \\
\hline
\end{tabular}

Table 6 Certified reference sample (European Reference Material ERM-CC580) and Tort 2 for $\mathrm{Hg}^{2+}$ analyzed in triplicates with DMA.

European Reference Material ERM-CC580
Tort-2

$\begin{array}{lc}\text { Recovery } \mathrm{Hg}^{2+} & 98.1 \% \pm 21.1 \\ \text { Certified value in Tort- } 2 & 270.00 \mathrm{ng} \mathrm{g}^{-1} \pm 60.00\end{array}$


Table 7 Sediment concentration of $\mathrm{Hg}^{2+}$ in Westbank area, Kuilsriver, Western Cape, South Africa determined by HPLC-ICP-MS and verified by analysis on DMA. Results are for duplicates and the mean of three determinations.

\begin{tabular}{lccc}
\hline Location & $\begin{array}{c}\text { HPLC-ICP-MS } \\
\text { Conc./ng g- } \\
\text { (w.wt) }\end{array}$ & $\begin{array}{c}\text { DMA } \\
\text { Conc. } / \mathrm{ng} \mathrm{g}^{-1} \\
\text { (w.wt) }\end{array}$ & $\begin{array}{c}\text { \% Difference } \\
\text { between methods } \\
\text { methods }\end{array}$ \\
\hline EKA 0-2 cm & $7.280 \pm 0.250$ & $7.481 \pm 1.752$ & 2.76 \\
EKA 2-4 cm & $3.055 \pm 0.022$ & $3.352 \pm 1.764$ & 5.65 \\
EKA 4-6 cm & $5.641 \pm 1.021$ & $5.979 \pm 0.622$ & 1.71 \\
EKA 6-8 cm & $4.644 \pm 1.015$ & $4.725 \pm 0.617$ & 3.88 \\
EKA 8-10 cm & $14.112 \pm 0.025$ & $14.167 \pm 0.406$ & 8.90 \\
EKB 0-2 cm & $3.251 \pm 1.520$ & $3.602 \pm 0.434$ & 9.74 \\
EKB 4-6 cm & $5.181 \pm 1.250$ & $5.235 \pm 1.703$ & 1.03 \\
EKB 6-8 cm & $2.824 \pm 1.250$ & $3.069 \pm 1.830$ & 7.98 \\
EKB 8-10 cm & n/a & n/a & \\
EKC 0-2 cm & $7.344 \pm 1.520$ & $7.351 \pm 1.055$ & 0.10 \\
EKC 4-6 cm & $6.080 \pm 1.051$ & $6.130 \pm 1.459$ & 0.82 \\
EKC 6-8 cm & $9.003 \pm 0.037$ & $9.034 \pm 0.888$ & 0.34 \\
EKC 8-10 cm & n/a & n/a & \\
EK 2 0-2 cm & $3.260 \pm 0.015$ & $3.342 \pm 0.330$ & -2.52 \\
EK 2 2-4 cm & $2.081 \pm 0.172$ & $2.074 \pm 0.290$ & 0.34 \\
EK 2 6-8 cm & $4.522 \pm 0.021$ & $4.410 \pm 0.240$ & 2.48 \\
EK 2 8-10 cm & $7.472 \pm 0.032$ & $7.354 \pm 0.210$ & 1.59 \\
\hline
\end{tabular}

Reported values are for the mean \pm S.D. of three determinations.

\section{Acknowledgement}

The CSIR, Natural Resources and the Environment (Stellenbosch, South Africa) is duly acknowledged for providing the samples, maps and DMA analysis data, for comparison to the data obtained by the apadted method for mercury in riverbed sediments. All services and materials were rendered as a paid service.

\section{References}

1 I. Ipolyi, P. Massanisso, S. Sposato, P. Fodor and P. Morabito, Concentration levels of total and methylmercury in mussel samples collected along the coasts of Sardinia Island (Italy), Anal. Chim. Acta 2004, 505, 145-151.

2 P. Houserová, D. Matějičck and V. Kubáň, High-performance liquid chromatographic/ion-trap mass spectrometric speciation of aquatic mercury as its pyrrolidinedithiocarbamate complexes, Anal. Chim. Acta, 2007, 596, 242-250

3 T.J. Kading, R.P. Mason and J.J. Leaner, Mercury contamination history of an estuarine floodplain reconstructed from a $210 \mathrm{~Pb}$-dated sediment core (Berg River, South Africa), Mar. Pollut. Bull., 2009, 59, $116-122$

4 N.J. Wagner and B. Hlathshwayo, The occurrence of potentially hazardous trace elements in five Highveld coals, South Africa, Int. J. Coal Geol., 2005, 63, 228-246

5 C.R. Williams, J.J. Learner, J.M. Nel and V.S. Somerset, Mercury concentration in water resources potentially impacted by coal-fired power stations and artisanal gold mining in Mpumalanga, South Africa, J. Environ. Sci. Health, Part A, 2010, 45(11), 1363-1373

6 K.E. Masekoameng, J. Leaner and J. Dabrowski, Trends in anthropogenic mercury emissions estimated for South Africa during 2000-2006. Atmos. Environ., 2010, 55, 4118-4125

7 M.A. Oosthuizen, J. John and V. Somerset, Mercury exposure in a low-income community in South Africa. S. Afr. Med. J. 100, 2010, 366-371

8 J.D.N. Pone, K.A.A. Hein, G.B. Stracher, H.J. Annegarn, R.B Finkleman, D.R. Blake, J.K. McCormack and P. Schroeder, P. (2007) The spontaneous combustion of coal and its by-products in the Witbank and Sasolburg coalfields of South Africa, Int. J. Coal Geol., $2007,72,124-140$

9 T.C. Davies and H.R. Mundalamo, Environmental health impacts of dispersed mineralization in South Africa, J. Afr. Earth Sci., 2010, 58, 652-666
10 M.N. Rashed, Monitoring of contaminated toxic and heavy metals, from mine tailings through age accumulation, in soil and some wild plants at Southeast Egypt. J. Hazard. Mat., 2010, 178, 739-746

11 K. Naicker, E.M. Cukrowska and T.S. McCarthy, Acid mine drain age arising from gold mining activity in Johannesburg, South Africa and environs. Environ. Pollut., 2003, 122, 29-40

12 E.M. Cukrowska, K. Govender and M. Viljoen, Ion mobility based on column leaching of South African gold tailings dam with chemometric evaluation, Chemosphere, 2004, 56, 39-50

13 K. Channa, J.O. Odland, T. Kootbodien, P. Theodorou, I. Naik, T.M. Sandanger and H.B. Röllin, Differences in prenatal exposure to mercury in South Africa communities residing along the Indian Ocean, Sci. Total Environ., 2013, 463-464, 11-19

14 G. Kuhn, Closeout summary report on the monitoring programme, findings and conclusions reached during the period from 30/09/2002 to March 2003, Gerry Kurn Environmental \& Hygiene, 2003, Piketberg, South Africa.

15 M.A. Dalvie and R. Ehrlich, Community mercury levels in the vicinity of peri-urban waste disposal sites and fossil fuel burning operations, Environ. Int., 2005, 32, 493-499

16 B. Inza, F. Ribeyre, R. Maury-Brachet and A Boudou, Tissue distribution of inorganic mercury, methylmercury and cadmium in the Asiatic clam (Corbicula fluminea) in relation to the contaminant levels of the water column and sediment, Chemosphere, 1997, 35, 2817-2836

17 A.L. Lawrence and R.P. Mason, Factors controlling the bioaccumulation of mercury and methylmercury by the estuarine amphipod Lectocheirus plumulosus, Environ. Pollut., 2001, 111, 217-231

18 V. Minganti, R. Capelli, G. Drava and R. De Pellegrini, Solubilization and methylation of $\mathrm{HgS}, \mathrm{PbS}$ and $\mathrm{SnS}$ by iodomethane: a model experiment for the aquatic environment, Chemosphere, 2007, 67, 1018-1024

19 M.C. Gabriel and D.G. Williamson, Principal biogeochemical factors affecting the speciation and transport of mercury through the terrestrial environment, Environ. Geochem. Health, 2004, 26, 421-434

20 C.R. Walters, V.S. Somerset, J.J. Learner and J.M. Nel, A review of mercury pollution in South Africa: current status, J. Environ. Sci. Health, Part A, 2011, 46, 1129-1137

21 J.J. Learner, J.D. Dabrowski, R.P. Mason, T. Resane, M. Richardson, M. Ginster, G, Gericke, C.R. Petersen, E. Masekoameng, P.A. Ashton and K. Murray, Mercury emission from point sources in South Africa, in Mercury Fate and Transport in the Global Atmosphere, (N. Pirrone and R. Mason, eds.), Springer Science and Business Media, 2009, DOI: 10.1007/978-0-387-93958-2-5

22 V. Somerset, J.J. Leaner, C.W. Williams, C.R. Petersen, R.P. Mason, E. Masekoameng, J. Dabrowski, P. MacMillan, P.J. Ashton, K. Murray, R. Bugan and A. Crouch, A National survey of mercury levels in South Africa s water resources. CSIR, Stellenbosch, 2010, Report No. CSIR/NRE/WR/IR/2010/002/B

23 O. Simon and A. Boudou, Direct and tropic contamination of the herbivorous carp Ctenopharyngodon idella by inorganic mercury and methylmercury, Ecotox. Environ. Safety, 2000, 50, 48-59

24 J.S. Landaluze, A. de Diego, J.C. Raposo and M. Madariaga, Methylmercury determination in sediments and fish tissues from the Nerbioi-Ibaizabal estuary (Basque Country, Spain), Anal. Chim. Acta, 2004, 508, 107-117

25 E. Van Wijngaarden, C. Beck, C.F. Shamlaye, E. Cernichiari, P.W. Davidson, G.J. Myers and T.W. Clarkson, Benchmark concentrations for methyl mercury obtained from the 9-year follow-up of the 'Seychelles Child Development Study', Neurotoxicol, 2006, 27, 702-709

26 W.F. Fritzgerald, C.H. Lamborg and C.R. Hammerschmidt, Marine biogeochemical cycling of mercury, Chem. Rev. Am. Chem. Soc., 2007, $107,641-662$

27 D.M. Sánchez , R. Martin, R. Morante, J. Marín and M.L. Munuera, Preconcentration speciation method for mercury compounds in water samples using solid phase extraction followed by reverse phase high performance liquid chromatography, Talanta, 2000, 52, 671-679

28 S.G. Hight and J. Cheng, Determination of methyl Hg and estimation of total $\mathrm{Hg}$ in seafood using high performance liquid chromatography and inductively coupled plasma-mass spectrometry: method development and validation, Anal. Chim. Acta, 2006, 567, 160-172

29 J.J.B. Nevado, R.C.R. Martín-Doimeadios, F.J.G. Bernado and 
M.J. Moreno, Determination of mercury species in fish reference materials by gas chromatography-atomic fluorescence detection after closed-vessel microwave-assisted extraction, J. Chromatogr. A, $2005,1093,21-28$

30 T. Stoichev, D. Amouroux, R.C.R. Martin-Doimeadios, M. Monperrus, O.F.X. Donald and D.L. Tsalev, Improvement of analytical performances for mercury speciation by on-line derivatization, cryofocussing and atomic fluorescence spectrometry, Appl. Spectrosc. Rev., 2006, 41, 591-619

31 E. Dabek-Zlotorzynska, E.P.C. Lai and A.R. Timerbaev, Capillary electrophoresis: state-of-the-art in metal speciation studies, Anal. Chim. Acta, 1998, 359, 1-26

32 M. Montes-Bayón, K.. DeNicola and J.A. Caruso, Liquid chromatography-inductively coupled plasma mass spectrometry. Journal of Chromatography, J. Chromatogr. A, 2003, 1000, 457-476

33 Ž. Kwokal, S.K. Sarkar, M. Chatterjee, S. Francisko vis-Bilinski, H. Bilinski, B.D. Bhattacharya and Md. Aftab Alam, An assessment of mercury loading in core sediments of Sunderban Mangrove Wetland, India (a preliminary report), Bull. Environ. Contam. Toxicol., $2008,10.1007 / \mathrm{s} 00128-008-9443-4$.
34 M. Baudrimont, J. Schäfer, V. Marie, R. Maury-Brachet, C. Bossy, A. Boudou and G. Blanc, Geochemical survey and metal bioaccumulation of three bivalve species in the Nord Médoc Salt Marshes (Gironde Estuary, France), Sci. Total Environ., 2005, 337, 265-280 .

35 L. Boszke, A. Kowalski, W. Szczuciñski, G. Rachlewicz, S. Lorenc and J. Siepac, Assessment of mercury mobility and bioavailability by fractionation method in sediments from coastal zone inundated by the 26 December 2004 tsunami in Thailand, Environ. Geol., 2006, 51, $527-536$.

36 W. Langseth, Determination of organic and inorganic mercury compounds by reverse-phase high-performance liquid chromatography after extraction of the compounds as their dithizonates, Anal. Chim. Acta, 1986, 185, 249-258

37 M.D. Malesuik, S.G. Cardoso, L. Bajerski and F.A. Lanzanova, A stability-indicating high performance liquid chromatographic (HPLC) assay for the simultaneous determination of atorvastatin and amlodipine in commercial tablets, J. AOAC Int., 2006, 89: 359-364

38 J. Canário, R. Prego, C. Vale and V. Branco, Distribution of mercury and monomercury in sediments of Vigo Ria, NW Iberian Peninsula, Int. J. Environ. Pollut., 2006, 101007/s11270-006-9317-5 